\title{
New-onset diabetes mellitus after renal transplantation
}

\author{
Dominika Goldmannova, David Karasek, Ondrej Krystynik, Josef Zadrazil
}

\begin{abstract}
Background and Aim. Diabetes mellitus is a very common metabolic disease with a rising incidence. It is both a leading cause of chronic renal disease and one of the most serious comorbidities in renal transplant recipients. New-onset diabetes after renal transplantation (NODAT) is associated with poor graft function, higher rates of cardiovascular complications and a poor prognosis. The aim of this paper is to review current knowledge of NODAT including risk factors, diagnosis and management.

Methods. A MEDLINE search was performed to retrieve both original and review articles addressing the epidemiology, risk factors, screening and management of NODAT. We also focused on microRNAs as potential biomarkers of NODAT. Results and Conclusion. Understanding the risk factors (both modifiable-e.g. obesity, viruses, and unmodifiable-e.g. age, genetics) may help reduce the incidence and impact of NODAT using pre- and post-transplant management. This can lead to better long-term graft function and general transplant success.
\end{abstract}

Key words: diabetes mellitus, renal transplantation, NODAT, microRNA

Received: August 25, 2015; Accepted with revision: February 2, 2016; Available online: February 29, 2016 http://dx.doi.org/10.5507/bp.2016.005

Department of Internal Medicine III - Nephrology, Rheumatology and Endocrinology, Faculty of Medicine and Dentistry, Palacky University Olomouc, Czech Republic

Corresponding author: Josef Zadrazil, e-mail: josef.zadrazil@fnol.cz

\section{INTRODUCTION}

Kidney transplantation is the treatment of choice for end-stage renal disease, as it allows maximal preservation of kidney function and improves the patients' quality of life. With the improved survival of patients and grafts, more attention is being paid to non-immunological complications of transplantation with significant impact on morbidity and mortality. Among other complications, new-onset diabetes mellitus after transplantation (NODAT) has become more prominent recently. The clinical significance of NODAT is reasonable as it leads to shorter survival of recipients, especially from cardiovascular and infectious complications, as well as of grafts. The purpose of this review is to summarize findings about NODAT, its pathogenesis, diagnosis, prevention and treatment. One part will be devoted on microRNAs (miRNAs), small non-coding RNA molecules playing a role in the pathogenesis of diabetic nephropathy (DN) and probably also in NODAT.

\section{ETIOLOGY AND PATHOGENESIS}

New-onset of diabetes mellitus (DM) occurs in approximately one third of renal transplant recipients, with the rate ranging between 7 and $46 \%\left(\right.$ ref. $\left.^{1-7}\right)$. The prevalence depends on the definition of DM, study design, immunosuppressives and time from transplantation.

Although the etiology of NODAT is still not understood, insulin resistance and insulin deficiency have been identified as key metabolic abnormalities that may develop through a variety of biochemical parameters ${ }^{8}$. Both traditional type $2 \mathrm{DM}$ risk factors and risk factors unique to transplant recipients are associated with NODAT (ref. ${ }^{1,7}$ ). Since NODAT is a very serious complication in patients after renal transplantation, identification of the risk factors may help prevent the condition. The risk factors can be divided into two groups, modifiable and non-modifiable. The non-modifiable risk factors are age, ethnic and genetic background, family history of type 2 DM, polycystic kidney disease and previous impaired glucose tolerance. The modifiable risk factors are obesity, viral infection, immunosuppressive drugs, human leukocyte antigen mismatch, donor gender and underlying renal disease. All these will be described below.

\section{RISK FACTORS}

\section{Non-modifiable risk factors Age}

People older than 40-45 years of age are at higher risk for developing NODAT (ref. ${ }^{3,11}$ ). Recipients older than 45 years are 2.9 times more likely to become diabetic post-transplant than younger recipients ${ }^{7}$. Age increases the risk for developing of NODAT by 1.5 fold for every 10 -years increase in age ${ }^{9}$.

\section{Race}

African American and Hispanic populations are at higher risk for NODAT than Caucasians ${ }^{1,7}$. African American and Hispanic patients have higher risk for development of NODAT because of their genetic polymorphisms which allow for more common disease prevalence compared to Caucasians ${ }^{10}$. This finding is consistent with 
the fact that the incidence of type 2 DM is significantly higher in African Americans then in Caucasians, in the general American population ${ }^{11-12}$.

\section{Family history}

Like type 2 DM, a positive family history of diabetes is considered a risk factor for NODAT. People with a history of DM among first-degree relatives should be identified to prevent the development of NODAT. A family history of diabetes increases the risk for NODAT up to seven times ${ }^{11}$.

\section{Genetic backround}

HLA mismatching has been associated with an increased risk of NODAT, although HLA phenotype cannot be considered a reliable risk factor for NODAT ( ref. $\left.^{3}\right)$. However, the results of published reports are contradictory. Some studies suggest an association between variants of the transcription factor 7-like 2 (TCF7L2) gene and NODAT (ref. ${ }^{13-14}$ ), while another study showed no significant relationship between TCF7L2 genotypes and the development of NODAT (ref. ${ }^{15}$ ). Moreover, research into the candidate genes is limited by its expense and inconvenience. Autosomal dominant or recessive polycystic kidney disease is also linked to NODAT (ref. ${ }^{16-17}$ ). A plausible mechanism for the association needs to be explained.

\section{Modifiable risk factors \\ Obesity}

Obese patients (BMI over $30 \mathrm{~kg} / \mathrm{m}^{2}$ ) have a relative risk for NODAT of 1.73 (95\% CI 1.57-1.90, $P<0.0001$ ) (ref. ${ }^{1}$ ) and obesity, along with age, is one of the strongest risk factors. The NODAT risk increases linearly for every $1 \mathrm{~kg}$ above $45 \mathrm{~kg}^{18}$. Adipose tissue produces leptin, tumor necrosis factor alpha (TNF $\alpha$ ), interleukins and adiponec$\operatorname{tin}^{19}$. Activation of the TNF $\alpha$ system is associated with insulin resistance through the generation of defects in the phosphorylation of the receptor and decrease in expression in insulin-sensitive glucose transporters. Induction of interleukin 6 synthesis is associated with alteration in glucose tolerance and is possibly a predictor of type 2 DM. For every $1 \mu \mathrm{g} / \mathrm{mL}$ decrease in adiponectin, the risk of developing NODAT is increased by $13 \%$ (ref. ${ }^{19}$ ).

\section{Proteinuria}

Proteinuria developing within 3-6 months after transplantation is a strong risk factor for NODAT ( ref. $\left.^{20}\right)$. Low-grade $(<1 \mathrm{~g} /$ day) and very low-grade $(<0.3 \mathrm{~g} /$ day $)$ proteinuria are independent risk factors for NODAT. There is a dose-dependent relationship across urinary albumin excretion categories (increasing risk from normoalbuminuria to albuminuria) with NODAT ( ref. $^{20}$ ).

\section{Perioperative hyperglycemia}

Perioperative hyperglycemia is also associated with NODAT $^{21-23}$. Hyperglycemia is caused by stress reaction to surgery (catecholamines), corticosteroids and restoration of renal function. Hyperglycemia reduces expression of interleukin-1-beta-converting enzyme- inhibitory protein which leads to apoptosis of the pancreatic beta cells. In their study, Chakkera et al. showed that among 377 patients who developed hyperglycemia during their transplantation hospitalization, $29 \%\left(\right.$ ref. $^{21}$ ) developed NODAT within the first year after transplantation. NODAT developed in just $4 \%$ (ref. $^{21}$ ) patients without inpatient hyperglycemia. Post-transplant inpatient hyperglycemia was defined as any bedside capillary blood glucose over 11.1 $\mathrm{mmol} / \mathrm{L}$.

\section{Infection}

Viral infections have been described as risk factors for NODAT. Transplanted patients are primarily more prone to infections than the general population. The main relevant viruses are chronic hepatitis $\mathrm{C}$ virus ( $\mathrm{HCV}$ ) and cytomegalovirus (CMV) infections correlate with NODAT.

\section{Hepatitis C}

A higher prevalence of type $2 \mathrm{DM}$ has been reported with HCV infection in the general population ${ }^{24}$. The infection is a significant comorbid condition in kidney transplant recipients and is associated with increased risk for both graft failure and mortality ${ }^{3}$. A 2005 meta-analysis of 10 studies of 2,502 patients found that anti-HCV-positive patients were nearly four times likely to have NODAT compared with uninfected individuals ${ }^{25}$. Hepatitis $\mathrm{C}$ virus elicits an apoptosis-like death of pancreatic beta-cells through an endoplasmic reticulum stress-involved, caspase 3 -dependent pathway ${ }^{26}$. Interferon has been the drug of choice for treating HCV infection in the non-transplant population for several decades. Its use in HCV-infected transplant patients has been largely avoided due to its propensity to elicit acute rejection of the allograft. Novel drugs (protease and nucleotide analog inhibitors) have been released to the market for treatment of HCV infection but they lack approval for use in transplant patients ${ }^{10}$.

\section{Cytomegalovirus}

Cytomegalovirus infection has been associated with DM 1. Kidney recipients who have symptomatic or asymptomatic CMV disease are at higher risk for developing NODAT. A study by Hjelmesaeth et al. reported that the incidence of NODAT was $6 \%$ in a control group and $26 \%$ (ref. $^{24}$ ) in a group with asymptomatic CMV infection defined by monitoring CMV pp65 protein in blood. A 2014 meta-analysis with 1,389 kidney transplant patients showed that CMV infection is a risk factor for increasing incidence of NODAT. Prophylaxis against CMV infection after kidney transplantation is strongly recommended ${ }^{27}$. Several mechanisms have been suggested to explain the impact of CMV on diminishing insulin secretion, such as beta cell damage directly by CMV and apoptosis or by infiltrative leukocytes or by induction of pro-inflammatory cytokines $^{27}$.

\section{Glucocorticoids}

Glucocorticoids are well known for leading to hyperglycemia by increasing glucose resistance, reducing insulin secretion and inducing beta cells apoptosis; they have 
Table 1. Risk factors associated with NODAT.

\begin{tabular}{lclccc}
\hline Risk factor & Length of study & Type of study & Number of patients & RR/OR & Ref. \\
\hline Age over 45 years & $1982-1999$ & Observational study & 2,078 & $\mathrm{RR}=2.90$ \\
Race - African American & $1996-2003$ & Observational study & 11,659 & $\mathrm{RR}=1.68$ & 1 \\
Race - Hispanic & $1996-2003$ & Observational study & 11,659 & $\mathrm{RR}=1.35$ & 1 \\
Obesity $\left(>30 \mathrm{~kg} / \mathrm{m}^{2}\right)$ & $1996-2003$ & Observational study & 11,659 & $\mathrm{RR}=1.73$ & 1 \\
Proteinuria $(>1 \mathrm{~g} /$ day) & $1985-2006$ & Observational study & 828 & $\mathrm{RR}=2.04$ & 20 \\
Perioperative hyperglycemia & $1999-2008$ & Observational study & 377 & $\mathrm{RR}=4.01$ & 21 \\
Polycystic kidney disease $(\mathrm{AD})$ & $1985-2000$ & Cohort study & 270 & $\mathrm{RR}=2.87$ & 16 \\
Hepatitis C infection & $1980-2004$ & Systematic review & 2,502 & OR=3.97 & 25 \\
CMV infection & $1990-2014$ & Meta-analysis & 1,389 & OR=1.94 & 27 \\
Steroids & $2004-2009$ & Meta-analysis & 25,837 & OR=1.42 & 32 \\
Tacrolimus versus cyclosporine & $2004-2009$ & Meta-analysis & 25,837 & OR=1.25 & 32 \\
Sirolimus & $1995-2006$ & Observational study & 20,124 & $\mathrm{RR}=1.36$ & 39 \\
\hline
\end{tabular}

RR (relative risk), OR (odds ratio)

been shown to reduce the expression of glucose transporter 2 and glucokinase ${ }^{28}$. The effect of glucocorticoids is dose-dependent.

Although postoperative withdrawal of corticosteroids remains a matter of controversy in clinical studies on renal transplantations, it is recognized that postoperative short-term pulsed therapy and low-dose maintenance therapy are not only safe but also reduce the risk of NODAT $\left(\right.$ ref. $\left.^{29}\right)$. Also single-center studies have demonstrated that oral prednisolone dose reduction to $5 \mathrm{mg}$ daily significantly improves glucose tolerance during the first year after transplantation ${ }^{30}$ while a $0.01 \mathrm{mg} / \mathrm{kg} /$ day increase in prednisolone dose is associated with a $5 \%$ (ref. ${ }^{31}$ ) risk of developing NODAT. A large retrospective study from years 2004-2006 with more than 25,000 transplant recipients demonstrated that steroid-free immunosuppression was associated with a significant reduction in the likelihood of developing NODAT compared to steroidcontaining regimens. The cumulative incidence rates of NODAT within three years post-transplant were $12.3 \%$ and $17.7 \%$ (ref. $^{32}$ ) in steroid-free and steroid-containing regimens, respectively.

\section{Calcineurin inhibitors}

Both cyclosporine and tacrolimus are strongly associated with NODAT development. Calcineurin inhibitors (CNIs) induce NODAT by decreasing insulin secretion and due to direct toxic effects on pancreatic beta cells. In their meta-analysis, Sharif et al. found that CNI-sparing strategies are associated with less delayed graft function, improved graft function and less NODAT (ref. ${ }^{33}$ ). Tacrolimus has usually been observed to be more diabetogenic ${ }^{6}$. A meta-analysis published in 2004 found that insulin-treated DM occurred in $9.8 \%$ of renal transplant recipients on tacrolimus versus $2.7 \%$ (ref. $^{6}$ ) of those on cyclosporine-based regimen. The DIRECT study showed that the incidence of NODAT at 6 months after transplantation was significantly lower in cyclosporine-treated patients than tacrolimus-treated patients ${ }^{34}$. It is not clear whether the effect of CNIs on glucose metabolism is dosedependent. Gourishankar et al. ${ }^{9}$ found no relationship between cyclosporine and tacrolimus trough blood levels at any time points ( 1 month, 6 month, 1 year, 5 year) and NODAT. In contrast, Maes et al. showed that the number of tacrolimus trough levels over $15 \mathrm{ng} / \mathrm{mL}$ during the first month after transplantation determined the development of NODAT (ref. ${ }^{35}$ ). Voclosporin is a novel calcineurin inhibitor being developed for organ transplantation. The PROMISE study showed that the incidence rates of NODAT for voclosporin were 1.6\%, 5.7\% and $17.7 \%$ (low, medium and high concentration, respectively) as compared with $16.4 \%$ (ref. $^{36}$ ) in tacrolimus.

\section{Sirolimus}

Sirolimus is a diabetogenic agent. Calcineurin inhibitors to sirolimus conversion therapy and tacrolimus withdrawal in a regimen consisting of tacrolimus and sirolimus were associated with a $30 \%$ increased incidence of impaired glucose tolerance ${ }^{37-38}$. Johnston et al. demonstrated that patients treated with sirolimus in combination with CNIs (cyclosporine or tacrolimus) had the highest incidence of NODAT $\left(\right.$ ref. $\left.^{39}\right)$.

Other immunosuppressive agents, azathioprine and mycophenolate mofetil (MMF) are not diabetogenic. The combinations of tacrolimus $+\mathrm{MMF}$ or cyclosporine $+\mathrm{MMF}$ are associated with lower rates of NODAT compared to tacrolimus+azathioprine ${ }^{40}$. The combination of either calcineurin inhibitor with sirolimus may be particularly diabetogenic, compared with the combination of a CNI with MMF ( ref. $^{32}$ ).

Table 1. summarizes the relevance of risk factors expressed as relative risk (RR) or odds ratio (OR).

\section{DIAGNOSIS}

NODAT usually occurs early after kidney transplantation. The estimated incidence rates in the United States are $9.1 \%$ at 3 months, $16 \%$ at 12 months, and $24 \%$ at 36 months (ref. ${ }^{1}$ ). 
In 2003, the International Consensus Guidelines on NODAT were published. They recommended that the diagnosis of NODAT should be based on the 2003 American Diabetes Association criteria for type 2 DM (ref. $\left.{ }^{3,4}\right)$. Diabetes mellitus is diagnosed by any of the following criteria:

1. Symptoms of DM (polyuria, polydipsia, unexplained weight loss) and random plasma glucose over $11.1 \mathrm{mmol} / \mathrm{L}$.

2. Fasting plasma glucose over $7 \mathrm{mmol} / \mathrm{L}$ ( $8 \mathrm{~h}$ of fasting).

3. Using oral glucose tolerance test with 2-hour plasma glucose over $11.1 \mathrm{mmol} / \mathrm{L}$ (this test should be performed using a glucose load containing the equivalent of $75 \mathrm{~g}$ of anhydrous glucose dissolved in water).

\section{FUTURE PERSPECTIVE OF NODAT}

Special attention is paid to microRNAs that have attracted a high level of interest lately. miRNAs are endogenously produced short noncording RNAs of 19-23 nucleotides that play an important role in modulating gene expression affecting almost every key cellular function ${ }^{41}$. They can bind to the 3' untranslated region of miRNA of protein-coding genes to down-regulate their expression ${ }^{42}$. miRNAs are potential sensitive biomarkers for human diseases (cancer, cardiovascular disease, autoimmune diaseases, etc.) and tissue injury. They are stable and easy to quantify in a non-invasive manner in plasma and urine ${ }^{43}$. A number of studies have aimed to clarify the repertoire of miRNAs in the development and progression of DN but there is no study on miRNAs and NODAT. miR-155 and miR-146a were found to be increased more than 5-fold in samples from DN patients compared to controls, and miR-155 expression was closely correlated with serum creatinine levels. During the induction and progression of the diasease in type 1 and type $2 \mathrm{DN}$ rat models, miR-155 and miR-146a were demonstraded to increase gradually ${ }^{44}$. Also, miR-126 can be used as a biomarker for pre-diabetes and DM. It is significantly lower in patients with impaired fasting glucose, impaired glucose tolerance or with DM than in healthy controls ${ }^{45}$. Another study showed that deregulation of miR-29 was involved in the pathogenesis of DN and insulin resistance and may thus be implicated in diabetic vascular complication. Patients with albuminuria showed significantly higher levels of urinary miR-29a than those with normal albuminuria ${ }^{46}$.

Accumulation of extracellular matrix proteins such as collagen (fibrosis) and mesangial expansion (hypertrophy) in the kidney mesangium and tubular compartments, along with podocyte dysfunction, are major hallmarks of DN, and contribute to renal failure in DM (ref. ${ }^{47-49}$ ). Transforming growth factor- $\beta 1$ (TGF- $\beta 1$ ) levels and signaling are enhanced in renal cells during the progression of DN. TGF- $\beta$ plays a key role in mesangial fibrosis and hypertrophy under diabetic conditions by inducing the expression of extracellular matrix proteins such as collagen and fibronectin ${ }^{48,50}$. miR-216a, miR-217 and key miR-200 family members were increased in mouse kidney glomeru- lar mesangial cells treated with TGF- $\beta$ and in kidney glomeruli from mouse models of DM ( ref. $^{51-52}$ ). In addition, miR-192, which is highely expressed in kidney, is upregulated in mouse kidney glomerular mesangial cells treated with TGF- $\beta$ and renal glomeruli from mouse models of type 1 and type 2 DM relative to the corresponding controls $^{49}$.

Therapeutic options may be focused on manipulating miRNA activity to attenuate disease progression. Inhibitors of miRNA expression include antagomirs which bind directly to miRNAs ${ }^{53}$ or miRNA sponges which contain tandem repeats of miRNA-binding sites ${ }^{54}$.

\section{MANAGEMENT OF NODAT}

\section{Pre-transplantation management}

Making an early diagnosis of NODAT is important because preventive measures can enhance the kidney transplant recipients ' chances for a better quality of life and prolong graft survival ${ }^{55}$. All candidates on a waiting list should undergo a baseline evaluation including age, a history of the risk factors (BMI, hypertension, dyslipidemia, smoking) and a family history. At-risk patients should then be counselled on lifestyle changes, diet, exercise and smoking cessation. Overweight patients should achieve a weight reduction of at least $7 \%\left(\right.$ ref. $^{56}$ ) of initial body weight. Physical activity of at least 150 minutes a week is recommended as a strategy for preventing NODAT ( ref. $^{57}$ ).

\section{Post-transplantation management}

The 2009 KDIGO recommendations suggest screening for NODAT with fasting blood glucose, oral glucose tolerance and/or $\mathrm{HbAlc}$ tests weekly during the first four weeks after transplantation, then three, six and nine months posttransplant and then yearly. Screening for NODAT should also be performed after starting treatment with glucocorticoids, sirolimus or CNIs (ref. ${ }^{58}$ ).

Immunosuppressive protocols should be individualized according to the risk of NODAT, but the potential benefit of altering an immunosuppressive regimen must be weighed against the risk of allograft rejection. Glucocorticoid doses should be decreased as soon as possible, but complete withdrawal is recommended only in patients with low immunological risk and no history of acute rejection episodes ${ }^{3}$. Prednisolone dose reduction to $5 \mathrm{mg} /$ day at one year has been associated with a decrease in glucose intolerance ranging from $55 \%$ to $34 \%$ (ref. ${ }^{30}$ ).

If lifestyle modifications alone are insufficient to control the hyperglycemia, pharmacotherapy targeting glucose metabolism should be initiated. The choice between insulin and oral hypoglycemic agents depends on the severity, timing and expected duration of hyperglycemia $^{59}$. Since corticosteroids are typically administered in the morning, a combination of intermediate and shortacting insulin administered several times during the day and corresponding to mealtimes may be required ${ }^{60}$. In less urgent cases, oral hypoglycemic medication is recommended. No hypoglycemic agent is contraindicated in kid- 
ney transplant recipients and there are no significant drug interactions with immunosuppressive drugs. Metformin as a first line agent in DM patients improves insulin sensitivity. The choice of metformin is dictated by the level of renal function. It is safe in patients with glomerular filtration rate over $50 \mathrm{~mL} / \mathrm{min}$ per $1.73 \mathrm{~m}^{2}$. One serious side effect is dyspepsia which can be aggravated by immunosuppressive agents used in kidney transplant recipients. Weight gain is common among solid organ recipients, with average weight gains of $8-14 \mathrm{~kg}$ in the first year posttransplantation $^{61}$. A Cochrane review and meta-analysis that included randomized controlled trials of over 12 weeks duration found metformin to be weight neutral in comparison to placebo or diet in the general population ${ }^{62}$. Compared to sulfonylureas, metformin had a weighted mean difference in weight of $-2.9 \mathrm{~kg}$ (95\% CI -4.4 to -1.1$)$ (ref. ${ }^{62}$ ). Sulfonylureas enhance insulin secretion and their use is also dictated by renal function. Thiazolidinediones are insulin sensitisers, rosiglitazone has been shown to improve glucose tolerance, insulin sensitivity, and even endothelial function ${ }^{63}$. Dipeptyl peptidase-4 inhibitors selectively foster insulin secretion without inducing hypoglycemia, which might be advantageous in kidney transplant recipients with NODAT. Dipeptyl peptidase-4 inhibition (vildagliptin, sitagliptin) in kidney transplant recipients with overt NODAT was found to be safe and efficient, providing a novel treatment alternative for this specific form of diabetes ${ }^{6466}$.

Acknowledgement: This review was financially supported by the Faculty of Medicine and Dentristy, Palacký University Olomouc, Czech Republic (grant no. IGA LF 2015 015).

Author contributions: DG: literature search and manuscript writing; DK, OK, JZ: literature search and critical reading; all authors: manuscript revision.

Conflict of interest statement: The authors state that there are no conflicts of interest regarding the publication of this article.

\section{REFERENCES}

1. Kasiske BL, Snyder JJ, Gilbertson D, Matas AJ. Diabetes mellitus after kidney transplantation in the United States. Am J Transplant 2003;3(2):178-85.

2. Chadban S. New-onset diabetes after transplantation should it be a factor in choosing an immunosuppressant regimen for kidney transplant recipients. Nephrol Dial Transplant 2008;23(6):1816-8.

3. Davidson J, Wilkinson A, Dantal J, Dotta F, Haller H, Hernández D, Kasiske BL, Kiberd B, Krentz A, Legendre C, Marchetti P, Markell M, Van der Woude FJ, Wheeler DC; International Expert Panel. Newonset diabetes after transplantation: 2003 International Consensus Guidelines. Proceedings of an international expert panel meeting Barcelona, Spain, 19 February 2003. Transplantation 2003;75(10 Suppl):SS3-SS24.

4. Expert Committee on the Diagnosis and Classification of Diabetes Mellitus. Report of the Expert Committee on the Diagnosis and Classification of Diabetes Mellitus. Diabetes Care 2003;26(S1):S5-S20.

5. Gunnarsson R, Arner P, Lundgren G, Magnusson G, Ostman J, Groth CG. Diabetes mellitus-a more-common-than-believed complication of renal transplantation. Transplant Proc 1979;11(2):1280-1.

6. Heisel O, Heisel R, Balshaw R, Keown P. New onset diabetes mellitus in patients receiving calcineurin inhibitors: a systematic review and meta-analysis. Am J Transplant 2004;4(4):583-95.

7. Cosio FG, Pesavento TE, Osei K, Henry ML, Ferguson RM. Posttransplant diabetes mellitus: increasing incidence in renal allograft recipients transplanted in recent years. Kidney Int 2001;59(2):732-7.

8. Krentz AJ, Dmitrewski J, Mayer D. Effects of immunosuppressive agents on glucose metabolism: implications for the development of post-transplant diabetes mellitus. Clin Immunother 1995;4:103-23.

9. Gourishankar S, Jhangri GS, Tonelli M, Wales LH, Cockfield SM. Development of diabetes mellitus following kidney transplantation: a Canadian experience. Am J Transplant 2004;4: 1876-82.

10. Peev V, Reiser J, Alachkar N. Diabetes mellitus in the transplanted kidney. Front Endocrinol (Lausanne) 2014;5:141.

11. Sumrani NB, Delaney V, Ding ZK, Davis $R$, Daskalakis $P$, Friedman EA, Butt KM, Hong JH. Diabetes mellitus after renal transplantation in the cyclosporine era--an analysis of risk factors. Transplantation 1991;51(2):343-7

12. Osei K, Gaillard, T Schuster, PD. Pathogenetic mechanisms of impaired glucose tolerance and type II diabetes in African-Americans. The significance of insulin secretion, insulin sensitivity, and glucose effectiveness. Diabetes Care 1997;20(3):396-404.

13. Kang ES, Kim MS, Kim YS, Hur KY, Han SJ, Nam CM, Ahn CW, Cha BS, Kim SI, Lee HC. A variant of the transcription factor 7-like 2 (TCF7L2) gene and the risk of posttransplantation diabetes mellitus in renal allograft recipients. Diabetes Care 2008;31(1):63-8.

14. Ghisdal L, Van Laecke S, Abramowicz MJ, Vanholder R, Abramowicz $D$. New-onset diabetes after renal transplantation: risk assessment and management. Diabetes Care 2012;35(1):181-8.

15. Musavi Z, Azarpira N, Sangtarash MH, Kordi M, Kazemi K, Geramizadeh B, Malek-Hosseini SA. Polymorphism of transcription factor-7-like 2 (TCF7L2) gene and new-onset diabetes after liver transplantation. Int J Organ Transplant Med 2015;6(1):14-22.

16. de Mattos AM, Olyaei AJ, Prather JC, Golconda MS, Barry JM, Norman DJ. Autosomal-dominant polycystic kidney disease as a risk factor for diabetes mellitus following renal transplantation. Kidney Int 2005;67(2):714-20.

17. Hamer RA, Chow CL, Ong AC, McKane WS. Polycystic kidney disease is a risk factor for new-onset diabetes after transplantation. Transplantation 2007;83(1):36-40.

18. Prasad GV, Kim SJ, Huang M, Nash MM, Zalzman JS, Fenton SS, Cattran DC, Cole EH, Cardella CJ. Reduced incidence of new onset diabetes mellitus after renal transplantation with 3-hydroxy-3-methylglutaryl-coenzyme A reductase inhibitors (statins). Am J Transplant 2004;4(11):1897-903.

19. Rodrigo E, Fernández-Fresnedo G, Valero R, Ruiz JC, Piñera C, Palomar R, González-Cotorruelo J, Gómez-Alamillo C, Arias M. New-onset diabetes after kidney transplantation: risk factors. J Am Soc Nephrol 2006;17(12 Suppl 3):S291-5.

20. Roland M, Gatault P, Al-Najjar A, Doute C, Barbet C, Chatelet V, Laouad I, Marlière JF, Nivet H, Büchler M, Lebranchu Y, Halimi JM. Early pulse pressure and low-grade proteinuria as independent long-term risk factors for new-onset diabetes mellitus after kidney transplantation. Am J Transplant 2008;8(8):1719-28.

21. Chakkera HA, Knowler WC, Devarapalli Y, Weil EJ, Heilman RL, Dueck A, Mulligan DC, Reddy KS, Moss AA, Mekeel KL, Mazur MJ, Hamawi K, Castro JC, Cook CB. Relationship between inpatient hyperglycemia and insulin treatment after kidney transplantation and future new onset diabetes mellitus. Clin J Am Soc Nephrol 2010;5(9):1669-75.

22. Luan FL, Stuckey LJ, Ojo AO. Abnormal glucose metabolism and metabolic syndrome in non-diabetic kidney transplant recipients early after transplantation. Transplantation 2010;89(8):1034-9.

23. Joss N, Staatz CE, Thomson AH, Jardine AG. Predictors of new onset diabetes after renal transplantation. Clin Transplant 2007;21(1):13643.

24. Hjelmesaeth J, SagedalS, Hartmann A, Rollag H, Egenad T, Halgen M, Nordal KP, Jenssen T. Asymptomatic cytomegalovirus infection is associated with increased risk of new-onset diabetes mellitus and impaired insulin release after renal transplantation. Diabetologia 2004:47(9):1550-6.

25. Fabrizi F, Martin P, Dixit V, Bunnapradist S, Kanwal F, Dulai G. Posttransplant diabetes mellitus and HCV seropositive status after renal transplantation: meta-analysis of clinical studies. Am J Transplant 2005;5(10):2433-40. 
26. Wang Q, Chen J, Wang Y, Han X, Chen X. Hepatitis C virus induced a novel apoptosis-like death of pancreatic beta cells through a caspase 3-dependent pathway. PLoS ONE 7(6): e38522. doi:10.1371/ journal.pone.0038522.

27. Behzad E, Mohsen M, Mahmood S, Mehrdad E, Mehrdad T. The impact of cytomegalovirus infection on new onset diabetes mellitus after kidney transplantation: a review on current findings. $J$ Nephropathol 2014;3(4):139-48.

28. Penfornis A, Kury-Paulin S. Immunosuppressive drug-induced diabetes. Diabetes Metab 2006;32(5 Pt 2):539-46.

29. Knight SR, Morris PJ. Steroid avoidance or withdrawal after renal transplantation increases the risk of acute rejection but decreases cardiovascular risk. A meta-analysis. Transplantation 2010;89(1):1-14.

30. Hjelmesaeth J, Hartmann A, Kofstad J, Egeland T, Stenstrøm J, Fauchald P. Tapering off prednisolone and cyclosporin the first year after renal transplantation: the effect on glucose tolerance. Nephro Dial Transplant 2001;16(4):829-35.

31. Hjelmesaeth J, Hartmann A, Kofstad J, Stenstrøm J, Leivestad T, Egeland T, Fauchald P. Glucose intolerance after renal transplantation depends upon prednisolone dose and recipient age. Transplantation 1997;64(7):979-83.

32. Luan FL, Steffick DE, Ojo AO. New-onset diabetes mellitus in kidney transplant recipients discharged on steroid-free immunosuppression. Transplantation 2011;91(3):334-41.

33. Sharif A, Shabir S, Chand S, Cockwell P, Ball S, Borrows R. Metaanalysis of calcineurin-inhibitor sparing regimens in kidney transplantation. J Am Soc Nephrol 2011;22(11):2107-18.

34. Vincenti F, Friman $S$, Scheuermann E, Rostaing $L$, Jenssen T, Campisto JM, Uchida K, Pescovitz MD, Marchetti P, Tuncer M, Citterio F, Wiecek A, Chadban S, El-Shahawy M, Budde K, Goto N; DIRECT (Diabetes Incidence after Renal Transplantation: Neoral C Monitoring Versus Tacrolimus) Investigators. Results of an international, randomized trial comparing glucose metabolism disorders and outcome with cyclosporine versus tacrolimus. Am J Transplant 2007;7(6):1506-14

35. Maes BD, Kuypers D, Messiaen T, Evenepoel P, Mathieu C, Coosemans W, Pirenne J, Vanrenterghem YF. Posttransplantation diabetes mellitus in FK-506-treated renal transplant recipients: analysis of inci dence and risk factors. Transplantation 2002;72(10):1655-61.

36. Busque S, Cantarovich M, Mulgaonkar S, Gaston R, Gaber AO, Mayo PR, Ling S, Huizinga RB, Meier-Kriesche HU; PROMISE Investigators The PROMISE study: a phase $2 \mathrm{~b}$ multicenter study of voclosporin (ISA247) versus tacrolimus in de novo kidney transplantation. Am J Transplant 2011;11(12):2675-84.

37. Teutonico A, Schena PF, Di Paolo S. Glucose metabolism in rena transplant recipients: effect of calcineurin inhibitor withdrawal and conversion to sirolimus. J Am Soc Nephrol 2005;16(10):3128-35.

38. Schold JD, Kaplan B, Chumbler NR, Howard RJ, Srinivas TR, Ma L, Meier-Kriesche HU. Access to quality: evaluation of the allocation of deceased donor kidneys for transplantation. J Am Soc Nephrol 2005;16(10):3121-7.

39. Johnston $\mathrm{O}$, Rose CL, Webster AC, Gill JS. Sirolimus is associated with new-onset diabetes in kidney transplant recipients. J Am Soc Nephrol 2008;19(7):1411-8.

40. Miller J, Mendez R, Pirsch JD, Jensik SC. Safety and efficacy of tacrolimus in combination with mycophenolate mofetil (MMF) in cadaveric renal transplant recipients. FK506/MMF Dose-Ranging Kidney Transplant Study Group. Transplantation 2000;69(5):875-80.

41. Fernandez-Valverde SL, Taft RJ, Mattick JS. MicroRNAs in $\beta$-cell biology, insulin resistance, diabetes and its complications. Diabetes 2011;60(7):1825-31.

42. Ambros V. MicroRNAs: tiny regulators with great potential. Cell 2001;107(7):823-6.

43. Kato $M$, Natarajan R. MicroRNA circuits in transforming growth factor- $\beta$ actions and diabetic nephropathy. Semin Nephrol 2012;32(3):253-60.

44. Huang Y, Liu Y, Li L, Su B, Yang L, Fan W, Yin Q, Chen L, Cui T, Zhang J, Lu Y, Cheng J, Fu P, Liu F. Involvement of inflammation-related miR-155 and miR-146a in diabetic nephropathy: implications for glomerular endothelial injury. BMC Nephrol 2014;15:142.

45. Liu Y, Gao G, Yang C, Zhou K, Shen B, Liang H, Jiang X. The role of circulating microRNA-126 (miR-126): a novel biomarker for screening prediabetes and newly diagnosed type 2 diabetes mellitus. Int J Mol Sci 2014;15(6):10567-77.

46. Peng $\mathrm{H}$, Zhong $\mathrm{M}$, Zhao W, Wang $\mathrm{C}$, Zhang J, Liu X, Li Y, Paudel SD, Wang Q, Lou T. Urinary miR-29 correlates with albuminuria and carotid intima-media thickness in type 2 diabetes patients. PLoS One 2013;8(12):e82607.

47. Chen S, Jim B, Ziyadeh FN. Diabetic nephropathy and transforming growth factor-beta: transforming our view of glomerulosclerosis and fibrosis build-up. Semin Nephrol 2003;23(6):532-43.

48. Kato $M$, Arce $L$, Natarajan R. MicroRNAs and their role in progressive kidney diseases. Clin J Am Soc Nephrol 2009;4(7):1255-66.

49. Kato $M$, Zhang J, Wang $M$, Lanting L, Yuan $H$, Rossi JJ, Natarajan $R$. MicroRNA-192 in diabetic kidney glomeruli and its function in TGFbeta-induced collagen expression via inhibition of E-box repressors. Proc Natl Acad Sci USA 2007;104(9):3432-7.

50. Yamamoto T, Nakamura T, Noble NA, Ruoslahti E, Border WA. Expression of transforming growth factor beta is elevated in human and experimental diabetic nephropathy. Proc Natl Acad Sci U S A 1993;90(5):1814-8.

51. Kato $M$, Arce $L$, Wang $M$, Putta $S$, Lanting $L$, Natarajan R. A microRNA circuit mediates transforming growth factor- $\beta 1$ autoregulation in renal glomerular mesangial cells. Kidney Int 2011;80(4):358-68.

52. Kato M, Wang L, Putta S, Wang M, Yuan H, Sun G, Lanting L, Todorov I, Rossi JJ, Natarajan R. Post-transcriptional up-regulation of Tsc-22 by Ybx1, a target of miR-216a, mediates TGF-\{beta\}-induced collagen expression in kidney cells. J Biol Chem 2010;285(44):34004-15.

53. Krützfeldt J, Rajewsky N, Braich R, Rajeev KG, Tuschl T, Manoharan M, Stoffel M. Silencing of microRNAs in vivo with 'antagomirs'. Nature 2005;438(7068):685-9.

54. Ebert MS, Neilson JR, Sharp PA. MicroRNA sponges: competitive inhibitors of small RNAs in mammalian cells. Nat Methods 2007;4(9):721-6.

55. Chakkera HA, Weil EJ, Swanson CM, Dueck AC, Heilman RL, Reddy KS, Hamawi K, Khamash H, Moss AA, Mulligan DC, Katariya N, Knowler WC. Pretransplant risk score for new-onset diabetes after kidney transplantation. Diabetes Care 2011;34(10):2141-5.

56. Lane JT, Dagogo-Jack S. Approach to the patient with new onset diabetes after transplant (NODAT). J Clin Endocrinol Metab 2011;96(11):3289-97.

57. Pham PT, Pham PM, Pham SV, Pham PA, Pham PC. New onset diabetes after transplantation (NODAT): an overview. Diabetes Metab Syndr Obes 2011;4:175-86.

58. Kidney Disease: Improving Global Outcomes (KDIGO) Transplant Work Group. KDIGO clinical practice guideline for the care of kidney transplant recipients. Am J Transplant 2009;9(Suppl 3):S1-155.

59. Yates CJ, Fourlanos S, Hjelmesaeth J, Colman PG, Cohney SJ. Newonset diabetes after kidney transplantation-changes and challenges. Am J Transplant 2012;12(4):820-8.

60. Palepu S, Prasad GV. New-onset diabetes mellitus after kidney transplantation: Current status and future directions. World J Diabetes 2015;6(3):445-55

61. Potluri K, Hou S. Obesity in kidney transplant recipients and candidates. Am J Kidney Dis 2010;56(1):143-56.

62. Saenz A, Fernandez-Esteban I, Mataix A, Ausejo M, Roque M, Moher D.Metformin monotherapy for type 2 diabetes mellitus. Cochrane Database Syst Rev 2005;(3):CD002966.

63. Voytovich MH, Simonsen C, Jenssen T, Hjelmesaeth J, Asberg A, Hartmann A. Short-term treatment with rosiglitazone improves glucose tolerance, insulin sensitivity and endothelial function in renal transplant recipients. Nephrol Dial Transplant 2005;20(2):413-8.

64. Haidinger M, Werzowa J, Hecking M, Antlanger M, Stemer G, Pleiner J, Kopecky C, Kovarik JJ, Döller D, Pacini G, Säemann MD. Efficacy and safety of vildagliptin in new-onset diabetes after kidney transplantation - a randomized, double-blind, placebo-controlled trial. Am J Transplant 2014;14(1):115-23.

65. Boerner BP, Miles CD, Shivaswamy V. Efficacy and safety of sitagliptin for the treatment of new-onset diabetes after renal transplantation. Int J Endocrinol 2014;2014:617638.

66. Strøm Halden TA, Åsberg A, Vik K, Hartmann A, Jenssen T. Short-term efficacy and safety of sitagliptin treatment in long-term stable renal recipients with new-onset diabetes after transplantation. Nephrol Dial Transplant 2014;29(4):926-33. 